\title{
The agroecology of an early state: New results from Hattusha
}

\section{Charlotte Diffey ${ }^{1}$, Reinder Neef ${ }^{2}$, Jürgen Seeher ${ }^{3}$ and Amy Bogaard ${ }^{4}$}

${ }^{1}$ School of Archaeology, Geography and Environmental Science, University of Reading

${ }^{2}$ Deutsches Archäologisches Institut Berlin

${ }^{3}$ Deutsches Archäologisches Institut Istanbul

${ }^{4}$ School of Archaeology, University of Oxford

\begin{abstract}
The discovery of a large underground silo complex with spectacular intact grain stores at the late Bronze Age Hittite capital of Hattusha provides a unique snapshot of crop production mobilised by the Hittite state. Use of crop stable isotope analysis and functional weed ecology alongside primary archaeobotanical analysis has revealed new insights into Hittite cultivation strategies while also shedding light on the ecology and politics of grain taxation by an ancient state.
\end{abstract}

\section{Introduction}

In 1999, a team led by Jürgen Seeher of the Deutsches Archäologisches Institut made a remarkable discovery while excavating a subterranean storage complex at the Hittite capital city of Hattusha: a series of intact storage chambers filled with hundreds of tonnes of charred cereal grain (Seeher, 2000; 2006). To the best of our knowledge this remains the largest archaeobotanical find in the world. Excavation of several tonnes of well-preserved plant material offers new insights into the nature of agricultural production at the Hittite capital in the early $16^{\text {th }}$ century BC. Previous discussions of Hittite agriculture have been limited by the quantitative archaeobotanical data available (a key exception being ongoing work at Kaman-Kalehöyük - Fairbairn \& Omura, 2005), and have instead relied on documentary evidence (e.g. Hoffner, 1974). In this study, the wealth of new archaeobotanical data from the Hattusha granary, combined with a multi-stranded agroecological approach, opens a new window onto Hittite crop husbandry methods and regimes, as well as on crop mobilization and taxation by this early state. 


\section{Hattusha}

The city of Hattusha is situated on the north-central Anatolian plateau, c. $210 \mathrm{~km}$ east of Ankara. The site lies at an altitude of $c .900-1250 \mathrm{~m}$ asl in a region characterized by fertile intermontane plains and river valleys (Branting, 1996). Palaeoclimatic reconstructions for the Bronze Age suggest that climatic conditions in this region were similar to those recorded today (Yakar, 2000:227; Dörfler et al. 2011; Schachner, 2011:36). Currently the plateau experiences warm, dry summers and cold, wet winters, with rainfall averaging c. $450 \mathrm{~mm} /$ year, but these conditions can often be unpredictable, leading to periods of intense drought (Seeher, 2006:83). Regional pollen records indicate that this region was heavily forested throughout the early Holocene (Roberts et al. 2011), but massive deforestation by the Hittites led to a dramatic decline in woodland species (Wright et al. 2015).

Hattusha was established around 1650 BC by Hattusili I. During the Old Kingdom period (c. 1700$1400 \mathrm{BC}$ ) it encompassed an area of $0.74 \mathrm{~km}^{2}$ known as the Lower City (Seeher, 2000; Bryce, 2002:12). During this phase, the site was dominated by the Büyükkale acropolis, which contained administrative and palatial buildings as well as a temple complex to the north-west (Figure 1a). The site was rediscovere during the late $19^{\text {th }}$ century $\mathrm{AD}$, with excavation beginning in the 1930 s by the Deutsches Archäologisches Institut (Seeher, 1995). In 1960-61 an underground structure was uncovered on the north-western slope of Büyükkale, behind the defensive postern wall of the Lower City (Seeher, 2000). Further excavation in 1999 revealed a massive subterranean grain storage complex measuring $118 \mathrm{~m}$ in length and 33-40 $\mathrm{m}$ in width (Seeher, 2006:49). Total capacity has been estimated at 7000-9000 $\mathrm{m}^{3}$ (Seeher, 2006:81), sufficient to store between 5512-7087 tonnes of cereal grain: enough to feed c. 20,000-30,000 people/year. Internally, the silo was divided into 32 individual storage chambers that were hermetically sealed and could be filled and emptied independently (Figure 1b). The silo was partially destroyed by fire during the early $16^{\text {th }}$ century BC, not long after it was built, causing the destruction of 12 of the 32 chambers (Seeher, 2006:49). Upon excavation, the most spectacular feature of this discovery was that some of these chambers were full, with hundreds of tonnes of intact charred cereal grain in layers c. $1.2 \mathrm{~m}$ thick (Dörfler et al. 2011) (Figure 2). Overall, excavation removed four tonnes of material from five individual chambers (Chambers 12, 28, 29, 30 and 32, highlighted in Figure 1b). This material is under study in a collaborative project between the School of Archaeology at the University of Oxford and the Deutsches Archäologisches Institut in Berlin (Diffey et al. 2017). 


\section{Methods}

Each excavated chamber was sampled both vertically and horizontally to assess compositional heterogeneity (see Supplementary information). Sample numbers per chamber varied due to differential preservation and exposure. Initial sub-sampling, scanning and preliminary identification of the Hattusha material was undertaken by Reinder Neef. Full quantification, identification and analysis of 45 samples was carried out at the School of Archaeology, University of Oxford from 2014-18. Compositional variation was explored using correspondence analysis (CA), which arranges samples along a set of axes (typically axis 1 and 2, which account for the most variation) based on species composition, and vice-versa. Associations among samples or species are shown as the direction and distance with which they diverge from the origin. CA was carried out using CANOCO 5 (Ter Braak \& Smilauer, 2012); in all diagrams shown here axis 1 was plotted horizontally and axis 2 vertically.

The analysis of crop stable isotope values was undertaken to interpret crop management systems in relation to water availability and soil nitrogen composition (see Supplementary information). In total, 64 subsamples, each containing 10 homogenized cereal grains, were selected for stable carbon and nitrogen isotope analysis (Supplementary Table 2). Individual sample errors for $\delta^{13} \mathrm{C}$ and $\delta^{15} \mathrm{~N}$ values were calculated using the within-run variability of the raw measurements and the known uncertainty of two reference standards using the approximation method (Kragten, 1994 - see Supplementary information). Accuracy or systematic error (u(bias)) following the Szpak et al. (2017) protocol was determined to be \pm 0.091 for $\delta^{13} \mathrm{C}$ and \pm 0.14 for $\delta^{15} \mathrm{~N}$ on the basis of the difference between the observed and known $\delta$ values of an in-house alanine and the long-term standard deviations of the alanine. Details of the analytical conditions are reported in Supplementary Tables 3 and 4.

Functional weed ecology was used to characterise crop growing conditions further, and to assess the overall labour-intensity of farming regimes. This method is based on the measurement of the functional traits of weed species, which estimate species' potential in relation to major ecological factors such as fertility and mechanical disturbance (Jones et al. 2000; Bogaard et al. 2016, 2018). This approach is complementary to stable isotope analysis of crops in that it provides a net assessment of arable fertility - to which practices such as water management and manuring may contribute - and brings in the additional factor of disturbance, determined by tillage and weeding practices (Bogaard et al. 2016, 2018). 
Discriminant analysis was used to make direct comparisons between archaeobotanical weed data and modern weed floras that developed under known conditions of high or low management intensity, using a model presented by Bogaard et al. (2018). This statistical technique combines relevant discriminating variables (here, functional ecological traits of weed species) to produce a linear equation that maximises the separation between pre-defined groups (here, modern fields managed under low- and high-intensity regimes). This equation was used to classify the Hattusha samples as unknown cases. Forty-four samples, each containing at least 100 weed seeds identified to species, were included. IBM SPSS Statistics 22 was used to perform the discriminant analysis.

\section{Results}

\section{Assemblage overview}

All 45 samples from the five excavated chambers contained a mixture of exceptionally well-preserved cereal grains, cereal chaff items, pulse seeds and weed seeds (Figure 3a-d; see Supplementary Table 5). Of these groups, grains of hulled barley (Hordeum vulgare) and grains or whole spikelets (grains enclosed by glumes) of the hulled wheats emmer (Triticum dicoccum) and einkorn (Triticum monococcum) dominate the assemblage. Hulled barley was the most commonly identified cereal, a preference that may be attributed to this species' tolerance of drought (Hillman, 1985; Nesbitt, 1996) in a region subject to dramatic rainfall fluctuation. Analysis of crop processing status based on the methodology developed by Jones $(1984 ; 1987)$ indicated that all cereals were in an advanced state of processing, having been subjected to threshing, winnowing, coarse- and fine-sieving, resulting in barley grain and hulled wheat spikelets (the latter represented primarily as grain due to a charring bias against chaff - see Supplementary Table 5). The predominance of cereal grain throughout the assemblage is in line with use of the silo as a storage depot for taxed produce (see below). More surprising was the sheer quantity of weed seeds present within every sample. Of the 100 taxa identified, 17 were found in over $50 \%$ of samples and seven were found in over $80 \%$ of samples. Common species included Bifora radians (Wild bishop), Ranunculus arvensis (Corn buttercup) and Vaccaria pyramidata (Cow herb), all of which are associated with arable agriculture today and native to the Central Anatolian plateau. Other plant taxa identified from the silo include potential cultivars: free-threshing wheat (Triticum aestivum/durum), bitter vetch (Vicia ervilia), lentil (Lens culinaris), grass pea (Lathyrus sativus) and a variety of small-seeded broad bean (Vicia faba var. minuta) (Neef et al. 2012). These species, however, were not abundant and likely represent crop contaminants. A 
possible exception is Vicia faba var. minuta, which was present in higher numbers throughout the silo and particularly in Chambers 12 and 32. This may indicate that pulses were grown within the same agricultural area(s) as the cereals in these chambers, and/or that these fields had been used for the cultivation of pulses in the past.

\section{Compositional analysis}

Figure 4a-b shows CA plots exploring the relationship among cereal crops and weed taxa, with samples coded by chamber number or shown as pie-charts. Samples from Chambers 29 and 30 occur in two distinct compositional groups: samples dominated by hulled barley grain are located towards the left (negative) end of axis 1, and samples with greater proportions of emmer grain and weed taxa towards the top (positive) end of axis 2. The position of samples from Chambers 12 and 32 towards the bottom (negative) end of axis 2 signifies that these chambers contained larger proportions of weed/wild taxa and pulse species. A further CA was performed on the basis of weed taxa only. Figure 5a shows that samples again cluster into separate groups by chamber. Chamber 12 has the most variable composition, containing large proportions of particular weed taxa (Bunias orientalis and other Cruciferae), and appears distinct from the other chambers. By contrast, Chambers 29 and 32 have relatively similar weed/wild compositions, a fact that was not apparent from Figure 4a. Finally, samples from Chamber 30 are clustered together towards the negative end of both axes. In Figure $\mathbf{4 b}$ samples from Chamber 30 were divided into those dominated by hulled barley and those dominated by glume wheat. Figure 5a-b, however, shows that, whilst variable in crop composition, the weed/wild species composition of this chamber is relatively uniform across all samples (see Supplementary Table 6 for CA acronyms used in Figure 5b). These chamber-specific combinations of plant taxa suggest that the crops stored within each chamber were cultivated under distinctive growing conditions.

\section{Stable carbon and nitrogen isotope analysis of cereals}

Supplementary Table 7 provides full results of the stable carbon and nitrogen isotope measurements of cereal samples from Hattusha. The C:N ratios of the archaeobotanical samples are variable but resemble those of modern experimentally charred cereal grains (Bogaard et al. 2013). Figure 6 shows the $\Delta^{13} \mathrm{C}$ values (see Supplementary information for the calculation of $\Delta^{13} \mathrm{C}$ values) of hulled barley and emmer grain, coded by chamber number. Overall, there is limited variability (standard deviations 
of 0.54 and $0.56 \%$, respectively, cf. Nitsch et al. 2015) within each taxon. Hulled barley values tend to be higher than emmer values (Welch two-sample T-test $=\mathrm{T}(50.454)=-3.55, \mathrm{p}=0.0008)$, likely due at least partly to physiological differences between wheat and barley (Araus et al. 1997; Wallace et al. 2013). Visible clustering of values by chamber in Figure 6 suggests variation in crop water status (see Supplementary Table 8 for statistical tests). Overall, the crops from Chambers 12 and 32 appear to have better water status, with some values indicative of well-watered conditions. By contrast, the crop values from Chambers 30 and 29 suggest drier conditions. These differences are consistent with rain-fed farming and exploitation of different growing conditions within the Hattusha hinterland.

Stable nitrogen isotope values of the two cereal types were similar (hulled barley $5.64 \pm 1.45 \%$, emmer $5.60 \pm 1.41 \%$ ) but also more variable than expected within a single growing condition (cf. Nitsch et al. 2015) and again exhibit clustering by chamber (Figure 7). Chambers 12 and 32 have significantly higher $\delta^{15} \mathrm{~N}$ values compared with values from Chambers 29 and 30 (see Supplementary Table 9 for statistical tests). When comparing these results with the manuring bands calibrated against rainfall to take account of aridity effects (Styring et al. 2016; 2017), Chambers 12 and 32 fall primarily within the high manuring bracket, and Chambers 29 and 30 within the low-medium manuring brackets. Use of manure has been well documented from agricultural communities in the Neolithic (e.g. Bogaard et al. 2013; Vaiglova et al. 2014) where its application improved soil fertility and tractability. Manure use, however, has two limiting factors: availability, and difficulty of transport (Wilkinson, 1994). The use of manure is typically limited to the immediate environs of a domestic settlement (e.g. Halstead, 2014). At Hattusha the range of $\delta^{15} \mathrm{~N}$ values suggests that crops from Chambers 12 and 32 were grown in fields that had preferential access to manure and that these farmers were engaged in a relatively intensive system of agriculture. By contrast, crops from Chambers 29 and 30 may have been grown in fields located further away from settlements, with less intensive management.

The combined results of carbon and nitrogen stable isotope analysis suggest that cereals from each individual chamber were cultivated under distinct growing conditions and land management regimes, and hence also at different locations. The cereals from Chambers 12 and 32 seem to have been grown under favourable watering conditions and with relatively high levels of soil enrichment. By contrast, crops from Chambers 29 and 30 were grown in drier conditions with lower inputs of manure.

\section{Functional ecological analysis of weeds and the intensity of cultivation}


Functional ecology on weed data from the Hattusha silo was used to assess the intensity of cultivation. Archaeobotanical samples were classified as deriving from low- or high-intensity regimes using a discriminant function that successfully distinguishes the weed flora of such systems in southern Europe and Morocco (Figure 8a) (Bogaard et al. 2018). From Figure 8b it is clear that the majority of samples from the silo are located towards the low-intensity end of the spectrum, with only two samples classified as high-intensity. In comparison with modern regimes, Hattusha samples correlate closely with fields from Haute Provence (SE France) and rain-fed terrace fields in Morocco. These low-intensity agricultural regimes were characterized by relatively low rates of disturbance (i.e. tillage and weeding) and moderate to low manuring. Overall, the agricultural regimes represented by samples from the five chambers appear to be characterized by low-input management. Figure $\mathbf{8 b}$ also echoes some of the chamber-based patterning that was evident above in CA and the results of the stable isotope analysis. For example, samples from Chamber 30 are clustered towards the low-input (negative) end of the discriminant function. By contrast, samples from Chamber 12 encompass a much greater range of values and include the only two samples classified as high-intensity. Thus, the results from functional weed ecological analysis and crop stable isotope analysis corroborate one another and are concurrent in the data they provide about the nature of farming at Hattusha.

\section{Combining the results of crop stable isotope and functional weed ecological analysis}

Modern agroecological studies have shown that functional weed traits and cereal stable isotope values correlate when comparing fields managed under multiple contrasting regimes (Bogaard et al. 2016, 2018). Archaeologically, however, it is often difficult to guarantee that identified weed taxa originate from the same fields as the cereal grains measured for stable isotope analysis. In the case of the Hattusha silo, similar chamber-specific patterns are mirrored independently by the results of the functional weed ecological analysis and crop stable isotope analysis, indicating that each chamber reflects a distinct set of growing conditions. Figures 9-10 show direct comparisons of stable carbon and nitrogen isotope values with the discriminant function scores from the weed ecological analysis on a sample-by-sample basis. With one exception (Figure 9a), all scatterplots show a significant positive correlation, indicating that samples with high stable isotope values also have high discriminant function scores. Sample data points also cluster to some extent by chamber number, particularly Chamber 30 . These results reinforce the inference that cereals stored in Chamber 30 were grown under a less intensive husbandry regime compared with cereals stored in other chambers. 
The results of multiple linear regression models (see Supplementary Table 10), however, show that there is no correlation between discriminant function score and crop stable isotope values within each chamber. These combined results are analogous with modern data from Morocco and Provence where a correlation between weed ecological traits and stable isotope values was found across contrasting regimes rather than within a (relatively homogeneous) agrosystem (Bogaard et al. 2016, 2018).

The combined variation in crop stable isotope and weed ecological data among the chambers suggests that each was used to store crops raised under distinct growing conditions and management regimes. While this does not preclude the use of a mixture of geographical farming locations and inter-annual harvest variation, the ecological variation indicated by both stable isotope analysis and functional weed ecology suggests that the silo was not used solely for storing annual harvests from the same regime. The significant differences in results between chambers (especially Chambers 12 and 30) are too extreme to reflect the same regime in different years. Crop stable nitrogen isotope values exhibit slow/small changes through time under a given manuring regime (Bogaard et al. 2007; Fraser et al. 2011). Furthermore, the discriminant analysis used to distinguish low-input/high-input regimes is based on multi-regional/multi-year modern weed surveys, and so includes a 'generous' allocation for inter-annual variation. The emerging hypothesis, therefore, is that each chamber of the Hattusha silo represents the produce of a different agricultural community or communities within the hinterland of Hattusha.

\section{Discussion}

\section{The range of crop husbandry regimes}

The patterning of archaeobotanical results on a chamber-by-chamber basis is a striking feature of the underground silo at Hattusha, and has been consistent in each form of analysis. This separation of the chambers strongly indicates that stored crops were being cultivated under an appreciable range of ecological conditions and were plausibly grown in a variety of locations. Certainly, the scale of potential grain storage represented by the underground silo is very unlikely to have been generated by a single arable estate or rural settlement. Using estimated capacities of the silo $\left(7000-9000 \mathrm{~m}^{3}\right)$ and early $20^{\text {th }}$ century barley yields $(1200 \mathrm{~kg} / \mathrm{ha})$ in the Çorum region in Central Anatolia (StratilSauer, 1933), the area of land needed to fill the whole silo to capacity would be approximately 46-59 
$\mathrm{km}^{2}{ }^{1}$ Moreover, it is improbable that the silo represents multiple years/harvests from the same area and regime, due to evident variation in especially $\delta^{15} \mathrm{~N}$ values (Bogaard et al. 2007; Fraser et al. 2011; Styring et al. 2017) and weed ecology (e.g. Bogaard et al. 2016). Instead, the results of this multistranded archaeobotanical analysis suggest that the silo was used for the collection and amalgamation of taxed arable produce from a certain variety of relatively extensive agricultural regimes.

Results from the combined stable isotope analysis and functional ecology, however, have shown that the statistical differences between chambers were not highly pronounced. This suggests that these regimes were not radically different from each other but instead represent variations on the same basic crop husbandry pattern, characterized by the use of traction to expand potential cultivation areas and restricted use of manuring and hand-weeding. Variation in crop growing conditions likely reflects a combination of locations and spatial factors, social factors and wealth distribution within the Hattusha hinterland. For example, the amount of available human and animal labour would have been a limiting factor within some communities. Similarly, the distribution and ownership of arable land would also have had an effect on local agroecologies. Ethnographic studies have shown that agricultural intensity decreases with distance from the settlement (e.g. Jones et al. 1999; Jones 2005; Halstead 2014:2078). It is plausible that such frictions of distance were exacerbated further by the expanding amount of land under cultivation and the increasing need for larger harvests.

\section{The politics of taxation}

Taxation in the Hittite state was based around the assessment of each individual household's agricultural output and labour force. The Hittite Law Code records that all inhabitants (excluding the elite) were subject to two forms of 'taxation' system. The luzzi service required each household to provide workers and livestock to cultivate crown lands twice a week (Yakar, 2000:267). This service would have been controlled by local governors, and any resultant produce was owned directly by the crown. The second system was the sahhan, a tax that required a portion of all crops, livestock, secondary products and manufactured goods to be paid to the crown (Yakar, 2000:267). Bryce (2002:77) has suggested that the Hattusha facility was a storage depot for produce generated via the sahhan or luzzi taxation systems. The range of crop growing conditions indicated by the agroecological data reported here supports this interpretation of the silo as providing storage for taxed produce, although it would be impossible to distinguish between these two means of taxation

\footnotetext{
${ }^{1}$ These calculations are based on the assessment that 1 tonne of cereal grain fills approximately $1.27 \mathrm{~m}^{3}$ of storage space (www.acqua-calc.com).
} 
archaeobotanically. It is conceivable that particular chambers within the silo were used to store cereals from particular rural districts or crown land estates within the Hattusha hinterland. Different settlements would necessarily employ somewhat distinct crop husbandry schemes due to the quality, quantity and topography of their arable land, as well access to human and animal labour. Overall, however, the nature of agriculture practised by Hittite farmers to generate crops for tax appears to have been broadly similar, exploiting increasingly expansive arable catchments with limited labour resources.

The Hattusha silo also visibly represents the power of the Hittite state to mobilize vast quantities of grain and its control over the agricultural economy. As recently synthesised in Scott's Against the Grain (2017), the use of cereals as the basis for taxation led to greater levels of state control across western Asia, due to the ease with which cereals could be monitored and stored by tax collectors (Scott, 2017:21). Cereals are also easier to harvest and transport on a large scale in comparison with pulse crops (Halstead 2014:103, 105, 114). While large-scale hermetic underground storage was evidently used primarily for hulled cereals at Hattusha, free-threshing cereals and pulses may have been stored above ground in pithos magazines (Neef 2001).

The construction of the underground silo at Hattusha not long after the establishment of the city itself and its placement in direct view of the royal acropolis (Seeher, 2006:49) attest to the importance of taxed cereal grain as a tangible manifestation of the Hittite king's wealth and success. Ironically, however, the hubris of amalgamating and storing large quantities of surplus arable produce made the state more vulnerable to catastrophic loss, as evidenced by the subsequent destruction of the silo. Whatever the eventual intended use of this produce (emergency famine supplies, seed corn, animal fodder etc. - see also Diffey et al. 2017; cf. Privitera, 2014) the fire would have been catastrophic and may have taken years to recover from. Moreover, the fact that the ruined grain was not removed and those chambers were never reused indicates that the Hittites may have chosen not to centralise crop storage on such a large scale after this event. At around the time of the large silo's (partial) destruction, individual pit silos on Büyükkaya (Silos 8, 9 and 11) were created (Seeher 2017:57-62). These were smaller in scale and more dispersed, and so less vulnerable to catastrophic loss. It is unclear whether these features were used in parallel with the large silo or after the fire. Subsequently, in the late $14^{\text {th }} /$ early $13^{\text {th }}$ century BC, smaller pit silos were constructed on the lower and middle plateaux of Büyükkaya (Seeher 2017:66-73). 


\section{Conclusions}

This multi-stranded archaeobotanical analysis of plant remains recovered from the underground silo at Hattusha has revealed a detailed snapshot of Hittite agriculture in the early $16^{\text {th }}$ century BC. Hittite farmers fulfilled their tax obligations by engaging in low-input, low variance arable agriculture based primarily around the cultivation of cereal crops able to provide reasonable yields even under marginal growing conditions. The separation of results by chamber, however, has also highlighted the level of variation that existed within this relatively extensive, low-input system, and has revealed the existence of multiple, distinct farming regimes. This range of crop husbandry regimes, as denoted by crop stable isotope analysis and functional ecological analysis of associated weed flora, indicates appreciable agroecological variability, suggesting that some farmers had access to better watered soils and supplies of manure. This study has also allowed new insight into the mobilization of arable produce by the Hittite state. The size and placement of the silo within the city walls attests to the importance of crop storage as well as the power derived from controlling the city's emergency supplies. Crops from the silo appear to have had distinct origins, demonstrating that the royal administration was able to tax the production of a varied agricultural economy across the rural hinterland.

\section{Acknowledgments}

The archaeobotanical work reported here was funded by the European Research Council (AGRICURB project, grant 312785, PI Bogaard) and awards to Diffey from the Wolfson-MarriotArchaeology-Graduate Scholarship, the Royal Pinner School and the Leverhulme Trade Charities Trust. Many thanks to Elizabeth Stroud for help with the stable isotopic work and useful comments on this paper; the latter were provided also by two anonymous reviewers.

\section{References}

Araus, J. L., Febrero, A., Buxo, R., Camalich, M., Martin, D., Molina, F., Rodriguez-Ariza, M. \& Romagosa, I. 1997. 'Changes in carbon isotope discrimination in grain cereals from different regions of the western Mediterranean Basin during the past seven millennia. Palaeoenvironmental evidence of a differential change in aridity during the late Holocene', Global Change Biology 3(2): 107-118.

Bogaard, A. 2005. 'Garden agriculture' and the nature of early farming in Europe and the Near East', World Archaeology 37: 177-196. 
Bogaard, A. 2011. Plant use and crop husbandry in an Early Neolithic Village: Vaihingen an der Enz, Baden-Württemberg, Frankfürter Archäologische Schriften, Habelt-Verlag: Bonn.

Bogaard, A., Heaton, T. H. E., Poulton, P. \& Merbach, I. 2007. 'The impact of manuring on nitrogen isotope ratios in cereals: archaeological implications for reconstruction of diet and crop management practices', Journal of Archaeological Science, 34: 335-343.

Bogaard, A., Fraser, R.A., Heaton, T.H.E., Wallace, M., Vaiglova, P., Charles, M., Jones, G., Evershed, R.P., Styring, A.K., Andersen, N.H., Arbogast, R.-M., Bartosiewicz, L., Gardeisen, A., Kanstrup, M., Maier, U., Marinova, E., Ninov, L., Schäfer, M. \& Stephan, E. 2013. 'Crop manuring and intensive land management by Europe's first farmers', Proceedings of the National Academy of Sciences 110 (31): 12589-12594

Bogaard, A., Hodgson, J., Nitsch, E., Jones, G., Styring, A., Diffey, C., Pouncett, J., Herbig, C., Charles, M., Ertuğ, F., Tugay, O., Filipovic, D \& Fraser, R. 2016. 'Combining functional weed ecology and crop stable isotope ratios to identify cultivation intensity: a comparison of cereal production regimes in Haute Provence, France and Asturias, Spain', Vegetation History and Archaeobotany 25: 57-73.

Bogaard, A., Styring, A., Ater, M., Hmimsa, Y., Green, L., Stroud, E., Whitlam, J., Diffey, C., Nitsch, E., Charles, M., Jones, G. \& Hodgson, J. G. 2018. 'From traditional farming in Morocco to early urban agroecology in northern Mesopotamia: combining present-day arable weed surveys and crop 'isoscapes' to reconstruct past agrosystems in (semi-)arid regions', Environmental Archaeology 23: 303-322.

Branting, S. 1996. 'The Alişar regional survey 1993-1994: A preliminary report', Anatolica 22: 14558.

Bryce, T. 2002. Life and Society in the Hittite World, Oxford University Press: Oxford.

Diffey, C., Neef, R. \& Bogaard, A. 2017. 'The archaeobotany of large-scale hermetic cereal storage at the Hittite capital of Hattusha', A. Schachner (ed.) Innovation versus Beharrung: Was macht den Unterschied des hethitischen Reichs im Anatolien des 2. Jahrtausends v. Chr.? Byzas 23. Ege Yayınları: Istanbul. pp. 185-202.

Dörfler, W., Harking, C., Neef, R., Pasternak, R. \& von den Driesch, A. 2011. 'Environment and Economy in Hittite Anatolia', in Genz, H. \& Mielke D. P. (eds.) Insights into Hittite History and Archaeology. Leuven: Peeters. pp. 99-124.

Fairbairn, A. \& Omura, S. 2005. 'Archaeological identification and significance of ÉSAG (agricultural storage pits) at Kaman-Kalehöyük, central Anatolia’, Anatolian Studies 55: 15-23.

Fraser, R., Bogaard, A., Heaton, T. H. E., Charles, M., Jones, G., Christensen, B. T., Halstead, P., Merbach, I., Poulton, P., Sparkes, D. \& Styring, A. K. 2011. 'Manuring and stable nitrogen isotope ratios in cereals and pulses: towards a new archaeobotanical approach to the inference of land use and dietary practices', Journal of Archaeological Science, 38: 2790 - 2804.

Halstead, P. 2014. Two Oxen Ahead: Pre-mechanized Farming in the Mediterranean, Blackwell: Oxford. 
Halstead, P. \& Jones, G. 1989. 'Agrarian ecology in the Greek islands: time stress, scale and risk', Journal of Hellenic Studies, 109: 41-55.

Hoffner, H. A. 1974. Alimenta Hethaeorum: Food Production in Hittite Asia Minor. American Oriental Series 55: Connecticut.

Jones, G. 1984. 'Interpretation of archaeological plant remains: ethnographic models from Greece', In W. van Zeist and W. A. Casparie (eds.) Plants and Ancient Man. Balkema: Rotterdam pp. 43-61.

Jones, G. 1987. 'A statistical approach to the archaeological identification of charred archaeobotanical remains', Circaea 6(2): 91-96.

Jones, G. 2005. 'Garden cultivation of staple crops and its implications for settlement location and permanence', World Archaeology 37: 164-176.

Jones, G., Bogaard, A., Halstead, P., Charles, M. \& Smith, H. 1999.' Identifying the intensity of crop husbandry practices on the basis of weed floras', Annual of the British School at Athens 94: 167189.

Jones, G., Bogaard, A., Charles, M. \& Hodgson, J. 2000. 'Distinguishing the effects of agricultural practices relating to fertility and disturbance: a functional ecological approach in archaeobotany', Journal of Archaeological Science 27: 1073-84.

Kragten, J. 1994. 'Tutorial review. Calculating standard deviations and confidence intervals with a universally applicable spreadsheet technique', Analyst 119(10): 2161-2165.

Neef, R., Cappers, R. T. J. \& Bekker, R. M. 2012. Digital Atlas of Economic Plants in Archaeology, Barkhuis \& Groningen University Library: Groningen.

Nitsch, E. K., Charles, M. \& Bogaard, A. 2015. 'Calculating a statistically robust $\delta 13 \mathrm{C}$ and $\delta 15 \mathrm{~N}$ offset for charred cereal and pulse seeds', Science and Technology of Archaeological Research 1: $1-4$.

Privitera, S. 2014. 'Long-term grain storage and political economy in Bronze Age Crete: Contextualizing Ayia Triada's silo complexes', American Journal of Archaeolgy 118: 429-449.

Roberts, N., Eastwood, W. J., Kuzucuoğlu, C., Fiorentino, G. \& Caracuta, V. 2011b. 'Climatic, vegetation and cultural change in the eastern Mediterranean during the mid-Holocene environmental transition', The Holocene 21(1): 147-162.

Schachner, A. 2011. Hattuscha. Die Hauptstadt der Hethiter: Auf der Suche nach dem sagenhaften Großreich der Hethiter, C. H. Beck: Munchen.

Scott, J. C. 2017. Against the Grain. Yale University Press: New Haven.

Seeher, J. 1995. 'Forty Years in the Capital of the Hittites: Peter Neve Retires from His Position as Director of the Hattuša-Boğazköy Excavations', The Biblical Archaeologist 58.2: 63-67. 
Seeher, J. 2000. 'Die Ausgrabungen in Boğazköy-Hูattuša 1999', Archäologischer Anzeiger 355-76.

Seeher, J. 2006. Ergebnisse der Grabungen an den Ostteichen und am mittleren BüyükkaleNordwesthang in den Jahren 1996-2000, Boğazköy-Berichete 8: Mainz.

Seeher, J. 2017. 'Die Besiedlung des Mittleren und Unteren Plateaus in hethitischer Zeit', J. Seeher (ed.) Büyükkaya II. Bauwerke und Befunde der Grabungskampagnen 1952-1955 und 1993-1998, Boğazköy-Hattuša Ergebnisse der Ausgrabungen 27. pp. 32-87.

Stratil-Sauer, G. 'Cereal production in Turkey, 1933', Economic Geography 9: 325-336.

Styring, A. K., Ater, M., Hmimsa, Y., Fraser, R., Miller, H., Neef, R., Pearson, J. A. \& Bogaard, A. 2016. 'Disentangling the effect of farming practice from aridity on crop stable isotope values: A present-day model from Morocco and its application to early farming sties in the eastern Mediterranean'. The Anthropocene Review 3: 1-21.

Styring, A. K., Charles, M., Fantone, F., Hald, M. M., McMahon, A., Meadow, R. H., Nicholls, G. K., Patel, A. K., Pitre, M. C., Smith, A., Soltysiak, A., Stein, G., Weber, J. A., Weiss, H. \& Bogaard, A. 2017. 'Isotope evidence for agricultural extensification reveals how the world's first cities were fed', Nature Plants 3: 1-11.

Szpak, P., Metcalfe, J.Z. and Macdonald, R.A. 2017. 'Best practices for calibrating and reporting stable isotope measurements in archaeology'. Journal of Archaeological Science: Reports 13: 609-616.

Ter Braak, C. F. J. \& Smilauer, P. 2012. CANOCO for Windows version 4.5. Centre for Biometry: Wageningen.

Vaiglova, P., Bogaard, A., Collins, M., Cavanagh, W., Mee, C., Renard, J., Lamb, A., Gardeisen, A., \& Fraser, R. 2014a. "An integrated stable isotope study of plants and animals from Kouphovouno, southern Greece: a new look at Neolithic farming', Journal of Archaeological Science 42: 201-215.

Wallace, M., Jones, G., Charles, M., Fraser, R., Halstead, P., Heaton, T. H. E. \& Bogaard, A. 2013. 'Stable carbon isotopes analysis as a direct means of inferring crop water statues and water management practices', World Archaeology, 45: 388-409.

Wilkinson, T. J. 1994. 'The structure and dynamics of dry-farming states in upper Mesopotamia [and comments and reply]', Current Anthropology 35: 483-520.

Wright, N. J., Fairbairn, A. S., Tyler Faith, J. \& Matsumura, K. 2015. 'Woodland modification in Bronze and Iron Age central Anatolia: an anthracological signature for the Hittite state?', Journal of Archaeological Science 55: 219-230.

Yakar, J. 2000. Ethonoarchaeology of Anatolia: Rural Socio-economy in the Bronze and Iron Ages. Emery and Claire Yass publications in Archaeology: Sydney. 